" reason to believe that this is the first specimen of a wild Capercailzie which has been shot in Northumberland in the memory of man."

Probab!y the writer's glee was somewhat chilled by the appearance in the same paper of an indignant letter from the Earl of Ravensworth, stating that the bird was reared in his park at Eslington from eggs sent from the Highlands, in the hope of naturalising the species in our country; the bird had strayed from its home.

All naturalists-and especially such as know this noble bird in its northern home-must hope that Lord Ravensworth will not be discouraged by this mishap, nor by others like it, but that he will persevere in his experiment. Eslington Park is situated in the valley of the Aln, near the foot of the Cheviots. Perhaps this is not the best part of the country in which to xear the birds, as, although not devoid of timber, the woodland there is scarcely that most suited to the Capercailzie. Pine woods on rocky ground are probably the best. Not far from Eslington, and partly on the Ravensworth estates, there is a superb piece of woodland and crag. Thrunton Crags, and the adjoining crags of Callaly, are very little known except to those who live near them, for they are out of the usual tourists' routes. But in all the county we do not know a district better worth a visit, nor one which so closely resembles the fir-clad mountain sides of southern Norway. The rocks are craggy sandstones, whilst those of Norway are mostly bosses of schists, and there is none of the water which gives such a charm to Norwegian scenery, but, in spite of these differences, the other resemblarces point out this as the Capercailzie's fitting home.

A wide area of high sandstone moorland stretches through Northumberland, attaining a height of over $I, 4,00$ feet at Simonside, near Rothbury, and approaching $I, 000$ feet in other places. This runs to the west of Alnwick, and thence north-west to Chillingham and away towards the Tweed. Another similar district branches from that of Simunside and spreads over a wide area around Harbottle, and between the Coquet and the Reed. Of the first-named range the crags of Thrunton and Callaly form conspicuous features. Only a small part of this range is wooded. It is much to be wished, for the sake of the springs and streams, that plantations were more numerous; and for many reasons, artistic and otkers, we could wish the same. In such parts of these wild hills as fir plantailons occur, the Capercailzie should do well; and, as plantations increase, we might hope that the birds would here find a permanent home. Besides the crags of Thrunton and Callaly we may note, as districts especially well suited to them, the fir woods of Harbottle; parts of the Duke of Northumberland's extensive park at Alnwick; and the wild forest-like park at Chillingham, the home of the far-famed "wild cattle." In years to come, when the plantations increase, Sir W. Armstrong's grounds at Cragside, near Rothbury, will afford the birds a shelter. Here, amidst a profusion of sub-Alpine plants, the Capercailzie should be quite at home.

W. TOPLEY

\section{NEWTON ON FORCE} $\mathbb{M}$ ANY English mathematicians are in the habit not sense-briefly, as cause of change of motion-but of regarding all other senses as loose and inaccurate. Of late years there has been an increasing tendency, largely due to Sir W. Thornson and Prof. Tait, to return to the methods of expressing dynamical principles used by Newton; so that at the present time his statement of the laws of motion is adopted to the exclusion of others which had usurped its place. This return to Newton has led to a very prevalent notion that for all the statements of fundamental dynamical principles current in modern English mathematical literature, we have his authority, and in particular for the above-mentioned restriction of the use of the word "force." As the authority of Newton seems to me to be here claimed without warrant, and as Newton's conception of force cannot be without interest, I propose to examine as briefly as possible what this conception was. In doing so I shall assume that the English word "force" is the equivalent of Newton's Latin word vis.

Newton commences the Principia with eirht definitions, among which are definitions of the intrinsic force of matter (zis insita or vis incrtia), impressed force, and centripetal force; he then proceeds to state and explain the laws of motion. From the chapters on the definitions and the laws of motion, we are able to infer with much probability the sense in which the word "force" is used. To show this it will only be necessary to translate a few extracts.

"Def. III.-The intrinsic force of matter is its power of resistance, by which every body, as far as depends on itself, persists in its state either of rest or of uniform rectilinear motion."

"Def. IV.-An impressect force is an action exerted on a body towards changing its state either of rest or of uniform rectilinear motion."

"Def. V.-A centripetal force is one by which bodies are pulled, pushed, or in any way tend from all parts towards any point as a centre."

"Just as in cases of impact and rebound bodies are equipollent whose velocities are reciprocally as their intrinsic forces; so in moving mechanical instruments agents are equipollent, and mutually support each other by their contrary efforts, whose velocities, estimated in the direction of the forces, are reciprocally as the forces." (Scholium to the Laws of Motion.) In the latter part of this quotation the word "forces" is used in the sense of impressed forces as defined by Def. IV.

One more quotation must be made; it is from Newton's comment on Def. III.: "-but a body exerts this force [vis inertia] only while a change is being made in its state by another force impressed on it."

In the quotaition from the Scholium, Newton is considering two cases in which bodies are to be moved; in one the power of resisting the motion arises from the intrinsic force of the body (or its wis inertice), in the other from the impressed force; in each case he seeks a measure of the effort required to move the bodies. Newton argues that, in the first case, this is to be measured by the intrinsic force and velocity conjointly, and in the second by the impressed force and [virtual] velocity conjointly ; implying that, in the first case, to give a body a certain velocity is equivalent to giving a body of twice its intrinsic force half that velocity; and in the second case-to take an example-that to lift a body vertically at a certain rate is equivalent to lifring a body of twice its weight at half the rate.

In this Scholium, in the case both of intrinsic force and of impressed force, the word "force" indicates some power of resistance to change of state; a general power due to the intrinsic force, and a special power due to the impressed force. And throughout it will be found that Newton's use of the word in its most general sense indicates a power of resistance, which professed metaphysicians are not alone in attributing to matter as essential to the conception of it. This most general sense of the word does not prevent Newton using it in any one of its special senses, and in particular very frequently for $i m$ pressed force, where no confusion is likely to arise ; but his language is very far from sanctioning the dictum that this is the sense and the only sense in which the word "force" may be used.

It is painful to refiect that Newton, great as he undoubtedly was, does not seem to have been sufficiently advanced to doubt whether there is such a thing as force, nor to have had a proper sense of the heinousness of his conduct in writing of accelerative force, motive force, and -worst of all-centrifugal force $\quad$ P. T. MAIN 